\title{
Elimination of mother-to-child transmission of HIV in South Africa: Rapid scale-up using quality improvement
}

\author{
S Bhardwaj, ${ }^{1}$ MB BS, MD, MPH; P Barron, ${ }^{2}$ BCom, FFCH; Y Pillay, ${ }^{3}$ PhD; L Treger-Slavin, ${ }^{1}$ BA, MPH; \\ P Robinson, ${ }^{3}$ BA (Health Services Mgmt \& Soc Sci), Adv Midwif, Adv Nurs Dyn; \\ A Goga,${ }^{4,5} \mathrm{MB}$ ChB, DTM\&H, DCH, MSc, MCH, FCPaed, MSc (Epidemiol); G Sherman, ${ }^{6,7} \mathrm{MB}$ BCh, PhD \\ UNICEF, South Africa \\ ${ }^{2}$ School of Public Health, Faculty of Health Sciences, University of the Witwatersrand, Johannesburg, South Africa \\ ${ }^{3}$ National Department of Health, Pretoria, South Africa \\ ${ }^{4}$ Department of Paediatrics and Child Health, Kalafong Hospital and Faculty of Health Sciences, University of Pretoria, South Africa \\ ${ }^{5}$ South African Medical Research Council, Pretoria, South Africa \\ ${ }^{6}$ National Health Laboratory Service, Johannesburg, South Africa \\ Department of Molecular Medicine and Haematology, Faculty of Health Sciences, University of the Witwatersrand, Johannesburg, South Africa
}

Corresponding author: S Bhardwaj (sbhardwaj@unicef.org)

Background. South Africa (SA) is committed to achieving the goal of eliminating mother-to-child transmission (MTCT) of HIV by 2015. To achieve this, universal coverage of quality antenatal, labour, delivery and postnatal services for all women has to be attained. Over the past decade, the prevention of mother-to-child transmission (PMTCT) programme has been scaled up to reach all healthcare facilities in the country. However, challenges persist in achieving $100 \%$ coverage and access to the programme.

Objectives. We describe the process undertaken by the National Department of Health (NDoH), in collaboration with partners, to develop, implement and monitor a data-driven intervention to improve facility, district, provincial and national PMTCT-related performance.

Methods. Between 2011 and 2013, the NDoH developed and implemented an intervention using data-driven participatory processes to understand facility-level bottlenecks to optimise PMTCT implementation and to scale up priority PMTCT actions nationally.

Results. There was remarkable improvement across all key indicators in the PMTCT cascade over the 3 years 2011 - 2013. Simple monitoring tools such as a visual dashboard and data for action reports were successfully used to improve the performance of the PMTCT programme across SA. MTCT has shown a significant downward trend.

Conclusions. It is feasible to implement district-level, data-driven quality improvement processes at a national scale to improve the performance of the PMTCT programme at the local level.

S Afr Med J 2014;104(3 Suppl 1):239-243. DOI:10.7196/SAMJ.7605

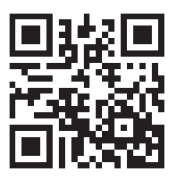

South Africa (SA) is in a unique position to move towards virtual elimination of new HIV infections in children by 2015 (defined as a $<2 \%$ rate of mother-tochild transmission (MTCT) of HIV at 6 weeks and a $<5 \%$ rate at 18 months. ${ }^{[1]}$

There has been a massive scale-up of the prevention of mother-to-child transmission (PMTCT) of HIV programme. The SA PMTCT Evaluation showed 3.5\% MTCT at $4-8$ weeks of age in $2010 .{ }^{[2]}$ When the survey was repeated in 2011, the MTCT rate was $2.7 \%$. The survey also showed that the proportion of eligible pregnant women taking triple antiretrovirals (ARVs) increased from $33.1 \%$ in 2010 to $46.2 \%$ in $2011 .^{[2]}$

The National Strategic Plan on HIV, STIs and TB 2012 - 2016 sets a goal of 'Reducing MTCT to less than $2 \%$ at six weeks post-delivery and less than $5 \%$ at 18 months of age by $2016{ }^{9[3]}$ To reach the ambitious goals of achieving virtual elimination of MTCT and putting all pregnant women on treatment, it is critical to scale up the PMTCT programme across all healthcare facilities in the country. It is also important to understand challenges and bottlenecks at facility and district level to ensure tailored and contextualised responses that will enable results to be achieved at the local level.

Several initiatives implemented in SA showed that decentralised planning and monitoring produce results. ${ }^{[4-6]}$ These initiatives were implemented in a few facilities and focused primarily around the use of data and working with programme managers to gain an in-depth understanding of data. Quality improvement initiatives implemented at facility level using participatory data-driven approaches and on-site monitoring and supervisory support have shown improvement in PMTCT coverage and service delivery. ${ }^{[7,8]}$

Between June and November 2011, the National Department of Health $(\mathrm{NDoH})$ developed an action framework for eliminating MTCT of HIV by 2015 in SA. The framework is entitled 'No child born with HIV by 2015 and improving the health and wellbeing of mothers, partners and babies in South Africa. ${ }^{\left[{ }^{[0]}\right.}$ The over-arching foundation of the national action framework is the need for evidencebased, accelerated programme scale-up and delivery of quality services with innovation. The framework proposed that data-driven action plans are needed for all the districts and provinces. These action plans could then inform provincial and district-specific work planning, implementation and monitoring.

This paper describes the process undertaken by the $\mathrm{NDoH}$, in collaboration with partners, to develop, implement and monitor a datadriven intervention to improve facility, district, provincial and national PMTCT-related performance.

\section{Methods}

The NDoH, supported by partners, recognised that the backbone of this intervention is a series of critical pathways called the PMTCT cascade that pregnant HIV-positive women need to move through 
to optimise their health. It is critical that the 'right intervention' is done at the 'appropriate time' in the cascade for all women, regardless of HIV status, to reduce the risk of MTCT. The cascade can be monitored through process indicators that are collected routinely as part of the District Health Information System (DHIS). These process indicators are collected in most countries. ${ }^{[10,11]}$

Fig. 1 outlines the cascade followed in SA from June 2011 to March 2013 (i.e. when SA was implementing WHO Option A PMTCT recommendations) and highlights the indicators used at critical points in the cascade to support tracking progress and identification of gaps in service delivery.

To understand the key challenges and gaps and to inform prioritisation of actions, data from the DHIS, the National Health Laboratory Service, the Saving Mothers report $^{[12]}$ and the SA PMTCT Evaluation ${ }^{[2]}$ were collated and analysed for the PMTCT cascade per district and province for 2010 (baseline). Using this information as a starting point, each district health team completed a bottleneck analysis of the obstacles and finalised an individualised action framework with potential key strategies that could improve access to and coverage of PMTCT programmes along the cascade, focusing on key indicators. Focus was on integrating PMTCT with routine interventions for reproductive, maternal, newborn and child health. The process was repeated in 2012 through the mid-year stock-taking exercise where progress with overcoming bottlenecks and activities in the 2011 Action Plan were tracked along with agreement on the next steps. Table 1 shows the phased approach and key actions adopted by the NDoH.

To facilitate development of an early warning system to alert programme managers and facility staff of attrition and gaps in the PMTCT cascade, a monitoring system was developed. Colour-coded dashboards comprising key indicators representing critical points in the PMTCT cascade were agreed on for tracking using the 'traffic light/ robot' approach. An indicator scored green when the target had been achieved, amber when there was progress from the baseline value without reaching the target, and red when there was no progress or downward movement. Quarterly data for action reports, including dashboards, were completed at district, provincial and national levels.

\section{Results}

Despite the scale-up of services in the past few years, gaps and challenges in achieving universal coverage for PMTCT across SA

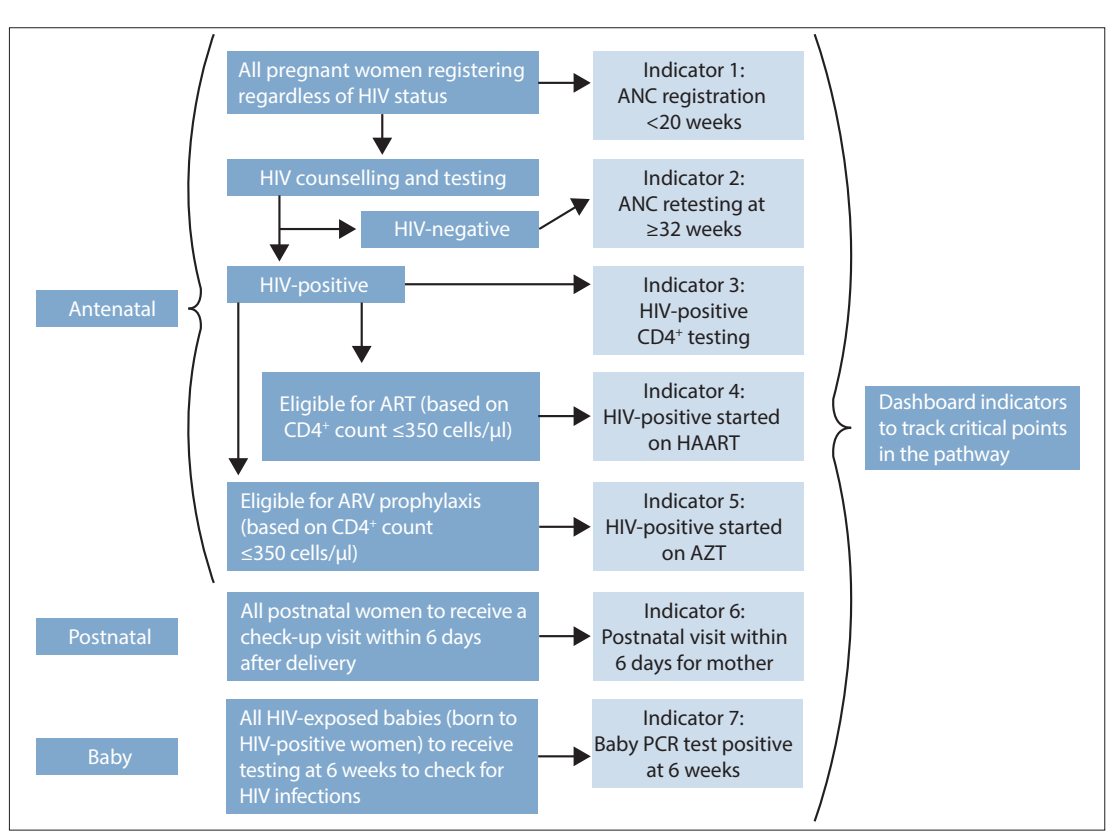

Fig. 1. Prevention of mother-to-child transmission cascade with associated indicators ( $A N C=$ antenatal care; $A R V=$ antiretroviral; $H A A R T=$ highly active antiretroviral therapy; $A Z T=$ zidovudine; $P C R=$ polymerase chain reaction). exist as a result of disparities across provinces, districts and sub-districts. The key challenges identified were gaps in quality of care at service delivery level and deficiencies in the quality of data. In some instances there was inaccurate or incomplete recording and reporting, lack of understanding of key indicators by healthcare providers and stakeholders, and lack of a systematic process at all levels of healthcare delivery.

The district case study presented in Table 2 showcases the key steps, viz. identification of bottlenecks and priority actions with tracking of progress through the dashboard.

In Lejweleputswa district there was an across-the-board improvement in the indicators. For example, the proportion of feedback and monitoring linked to action

\section{Table 1. Phased approach to PMTCT of HIV adopted by the NDoH between June 2011 and June 2013}

\begin{tabular}{|c|c|c|c|c|}
\hline Phases & Time period & Decentralised planning and action & Monitoring and management & Results achieved \\
\hline 1 & $\begin{array}{l}\text { June } 2011 \text { - } \\
\text { June } 2012\end{array}$ & $\begin{array}{l}\text { Review data from different sources to } \\
\text { understand bottlenecks and prioritise } \\
\text { actions; agree on key roles and } \\
\text { responsibilities and accountability } \\
\text { mechanisms }\end{array}$ & $\begin{array}{l}\text { Quarterly data for action reports } \\
\text { with dashboards tracking } \\
\text { progress for each district and } \\
\text { province; management and } \\
\text { co-ordination mechanisms } \\
\text { improved with accountability at } \\
\text { each level }\end{array}$ & $\begin{array}{l}\text { National, nine provincial and } 52 \\
\text { district PMTCT action frameworks } \\
\text { available; quarterly dashboards and } \\
\text { data for action reports used to track } \\
\text { progress; partnership frameworks } \\
\text { available to define roles of partners }\end{array}$ \\
\hline 2 & $\begin{array}{l}\text { July } 2012 \text { - } \\
\text { June } 2013\end{array}$ & $\begin{array}{l}\text { Progress reviewed through tracking in } \\
\text { the PMTCT cascade and dashboard } \\
\text { indicators; persistent challenges and } \\
\text { downward trends in an indicator } \\
\text { prioritised for action and monitored } \\
\text { closely }\end{array}$ & $\begin{array}{l}\text { Mid-year stock-taking exercise } \\
\text { conducted for all nine provinces } \\
\text { and } 52 \text { districts to review } \\
\text { progress and prioritise actions } \\
\text { for bottlenecks }\end{array}$ & $\begin{array}{l}\text { Better understanding per district and } \\
\text { province of persistent bottlenecks and } \\
\text { priority actions implemented }\end{array}$ \\
\hline
\end{tabular}


Table 2. District case study: Lejweleputswa District, Free State Province*

\begin{tabular}{|c|c|c|c|c|c|}
\hline \multicolumn{6}{|l|}{ Step 1: Data review } \\
\hline \multicolumn{6}{|c|}{ Analysis of data (Fig. 2) completed for the key indicators in the PMTCT cascade } \\
\hline \multicolumn{6}{|c|}{ Step 2: Bottleneck analysis and prioritisation of actions } \\
\hline \multicolumn{6}{|c|}{ Bottlenecks were identified during discussions reviewing the data and priority actions were listed as follows: } \\
\hline \multicolumn{2}{|l|}{ Key bottleneck } & \multicolumn{4}{|c|}{ Example of actions } \\
\hline \multicolumn{2}{|l|}{ Low rate of early antenatal registration ( $<20$ weeks) } & \multicolumn{4}{|c|}{$\begin{array}{l}\text { Provide antenatal services daily at the health facility; work with community } \\
\text { structures to assist with mobilisation and information sharing on early antenatal } \\
\text { registration; involve partners (e.g. Brothers for Life) and males in ANC. }\end{array}$} \\
\hline \multicolumn{2}{|c|}{$\begin{array}{l}\text { Low rate of } \mathrm{CD} 4^{+} \text {testing for } \mathrm{HIV} \text {-positive women (to assess } \\
\text { eligibility for ARV treatment) }\end{array}$} & \multicolumn{4}{|c|}{$\begin{array}{l}\text { Ensure SOPs are followed at clinic level and all HIV-positive women are } \\
\text { assessed for eligibility including } \mathrm{CD}^{+} \text {counts }\end{array}$} \\
\hline \multicolumn{2}{|c|}{$\begin{array}{l}\text { Low rate of antenatal clients initiated on PMTCT prophylaxis or } \\
\text { on ARV treatment based on eligibility }\left(\mathrm{CD} 4^{+} \text {counts }>350 \text { cells } / \mu \mathrm{l}\right. \\
\text { or }<350 \text { cells } / \mu \mathrm{l} \text {, respectively) }\end{array}$} & \multicolumn{4}{|c|}{$\begin{array}{l}\text { Support and strengthen implementation of basic ANC by all clinics that } \\
\text { have received training; train remaining facilities in basic ANC; improve } \\
\text { referral systems linking ANC and treatment and laboratory systems }\end{array}$} \\
\hline \multicolumn{6}{|c|}{ Step 3: Tracking progress by monitoring trends in the PMTCT cascade and the dashboards (Fig. 3) } \\
\hline \multicolumn{6}{|c|}{$\begin{array}{l}\text { Close monitoring was supported by the colour-coded 'robot' dashboard that prompted programme managers to review the critical points where } \\
\text { there was no or little improvement. Scoring progress in key indicators from } 2010 \text { - } 2012 \text { were as follows: }\end{array}$} \\
\hline Indicators & $2010, \%$ & $2011, \%$ & $2012, \%$ & Scoring ${ }^{\dagger}$ & National target $2012, \%$ \\
\hline ANC 1st visit $<20$ weeks & 43 & 48 & 54 & Amber & 60 \\
\hline $\mathrm{ANC}$ client $\mathrm{CD} 4^{+}$test rate & 86 & 92 & 97 & Green & 80 \\
\hline ANC initiated on AZT during ANC rate & 86 & 99 & 108 & Green & 85 \\
\hline ANC initiated on HAART rate & 62 & 67 & 80 & Amber & 90 \\
\hline ANC clients $\geq 32$ weeks retesting rate & 31 & 51 & 51 & Green & 50 \\
\hline Postnatal care mother visits within 6 days rate & 23 & 70 & 80 & Green & 40 \\
\hline Baby PCR test rate at 6 weeks & 105 & 104 & 105 & Green & 100 \\
\hline
\end{tabular}

of HIV-positive antenatal women started on ARV therapy improved from $62 \%$ in 2010 to $80.3 \%$ in 2012 , and early antenatal registration improved from $42.8 \%$ in 2010 to $54 \%$ in 2012 (Figs 2 and 3).

The oversight management and co-ordination of response with key stakeholders as well as facility-level actions to address the gaps identified during the bottleneck analysis have led to concrete results, and the increases in this district are therefore much greater than the increases in the national averages.

The example illustrated in this case study reflects the improvement seen across the PMTCT cascade in all 52 districts. This in turn has led to an improvement in overall programme performance at national level and a dramatic decrease in MTCT transmission rates for SA.

Fig. 4 illustrates how key national indicators along the PMTCT cascade changed over a 3-year period (2010 - 2012). There was improvement in early antenatal registration from $37 \%$ to $43 \%$, and the antenatal retesting rate for women with a negative result on the

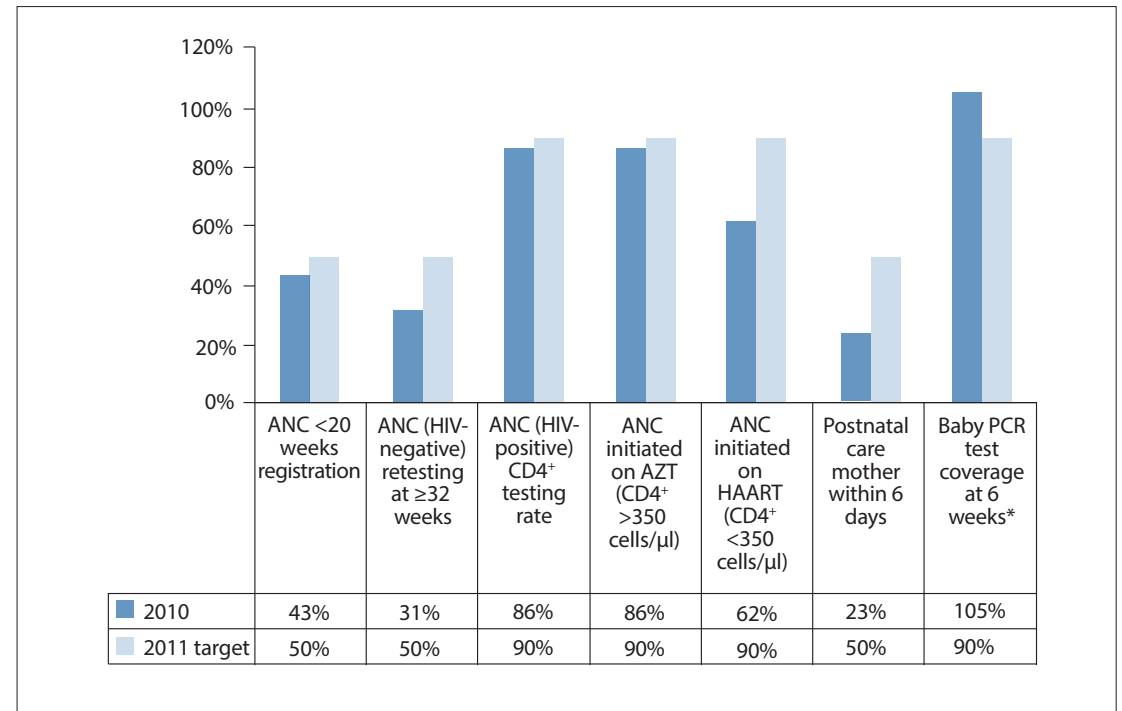

Fig. 2. Lejweleputswa District prevention of mother-to-child transmission cascade 2010 with targets (District Health Information System data). (ANC = antenatal care; $A Z T=$ zidovudine; HAART = highly active antiretroviral therapy; $P C R=$ polymerase chain reaction). ${ }^{*} A l l ~ H I V$-positive exposed babies.

first antenatal HIV test increased from $28 \%$ in 2010 to $47 \%$ in 2012 . There has been a remarkable improvement across all indicators in the PMTCT cascade at the national level. 


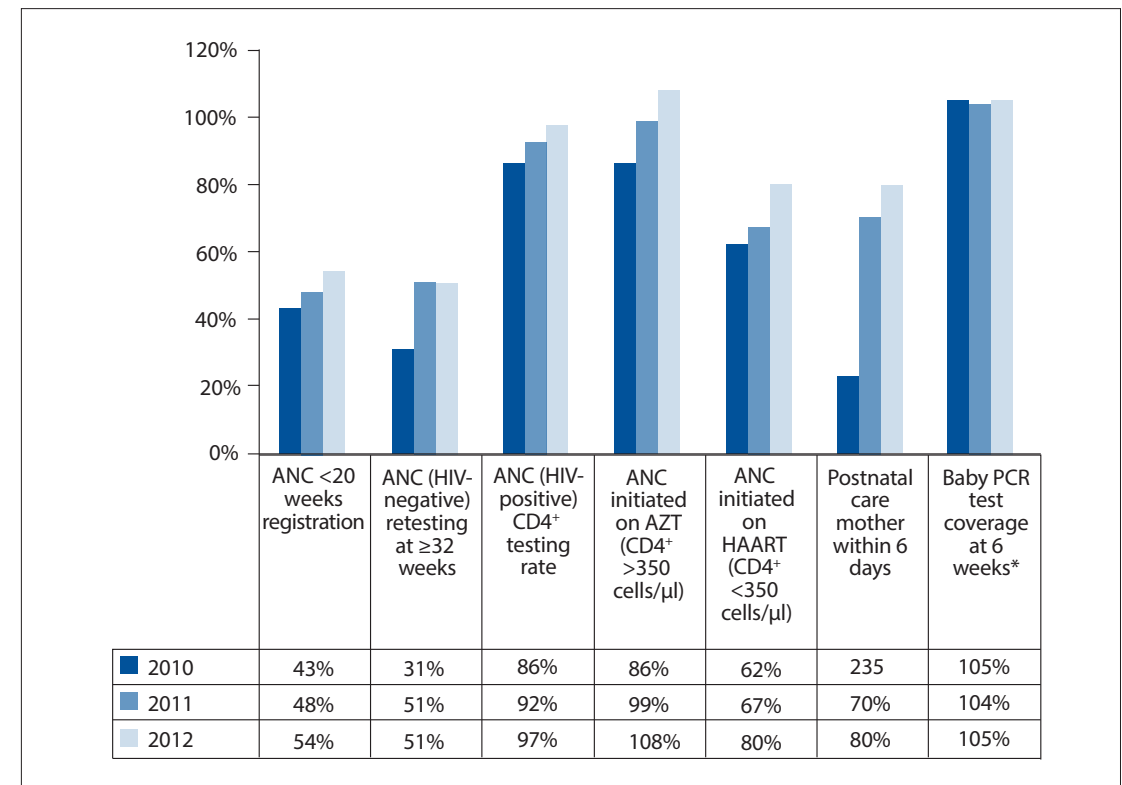

Fig. 3. Lejweleputswa District prevention of mother-to-child transmission cascade 2010 -2012 (District Health Information System data). (ANC = antenatal care; $A Z T=$ zidovudine; HAART = highly active antiretroviral therapy; $P C R=$ polymerase chain reaction). ${ }^{*} A l l$ HIV-positive exposed babies.

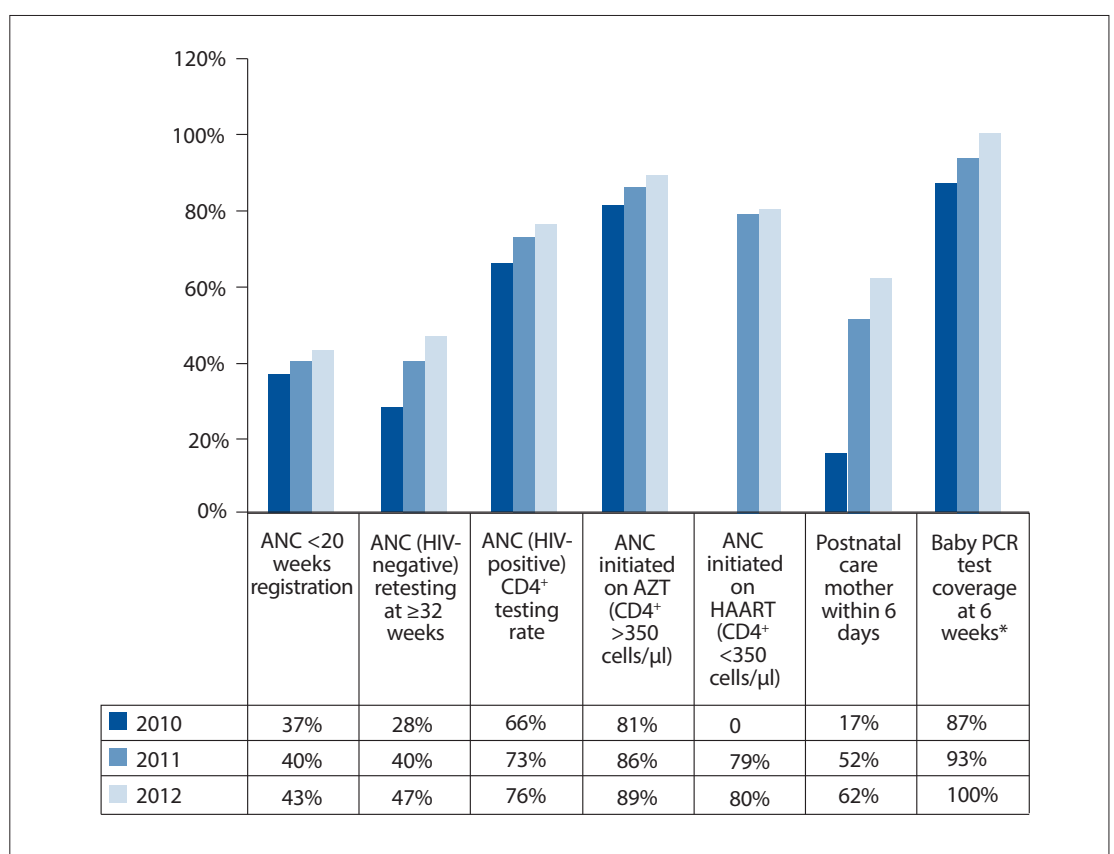

Fig. 4. National trends in the prevention of mother-to-child transmission indicators 2010 - 2012 (District Health Information System data). ( ANC = antenatal care; $A Z T=$ zidovudine; $H A A R T=$ highly active antiretroviral therapy; $P C R=$ polymerase chain reaction). ${ }^{*} A l l$ HIV-positive exposed babies.

The quality improvement process for PMTCT has resulted in critical actions:

- Co-ordination mechanisms functioning at national, provincial and district levels were strengthened to support monitoring and co-ordination of the programme, including regular review of the dashboards and data for action reports.

- There was large-scale implementation of capacity-building workshops with mentor- ing plans for healthcare staff at facility level supporting the implementation of priority actions as identified through the bottleneck analysis and dashboards.

- Community engagement was prioritised; including improving co-ordination among stakeholders and their work in PMTCT.

In addition, a number of programmatic priorities were identified:
- Meet the family planning needs of all women in the reproductive age group.

- Improve the involvement of males and communities for increased ownership and participation in service delivery.

- Ensure universal access to HIV counselling and testing and care and support services.

- Provide comprehensive quality antenatal care for all women.

- Provide ARV prophylaxis or treatment (based on eligibility criteria) and extend care and treatment through the postnatal period.

- Improve linkages and referrals of infants diagnosed with HIV for appropriate treatment and care.

- Improve tracking for early infant diagnosis for all HIV-exposed infants through the breastfeeding period.

- Ensure accessibility of services through integration of healthcare services for all women and children.

- Improve safe infant feeding practices for all babies (regardless of HIV exposure).

- Track progress on a monthly basis at facility level to ensure understanding of bottlenecks, and take corrective action.

- Use data as a tool for programme planning, action and monitoring.

\section{Conclusion}

The process adopted by SA shows that large-scale implementation of data-driven decentralised planning and monitoring using quality improvement tools results in improving the understanding of bottlenecks and prioritising actions at local levels. This supports improvement in programme performance across the PMTCT cascade.

However, given existing inequalities, unequal effort may be needed to ensure equal service access. In districts and provinces with high MTCT rates and gaps in the cascade, additional efforts are required to improve systems to reduce MTCT rates and access to care for mothers and infants.

With this continued effort, SA is on track to meet the goal of virtual elimination of MTCT by 2015. Efforts are ongoing to realise the vision of the action framework, viz. 'No child born with HIV and improving the health and well being of mothers, babies and partners' in SA by 2015 .

Acknowledgements. The work described in this article is a result of contributions by several individuals supporting the PMTCT programme, members of the PMTCT technical working group, PMTCT steering committees at national and provincial levels, provincial PMTCT co- 
ordinators, technical and implementing partners, facility healthcare staff and members of civil society.

\section{References}

1. Human Sciences Research Council. HIV/AIDS in South Africa: At last the glass is half full. Plenary Session 3, AIDS Conference, Durban, South Africa, 20 June 2013. http://www.hsrc.ac.za/en/media-briefs/hiv-aidsstis-and-tb/plenary-session-3-20-june-2013-hiv-aids-in-south-africa-at-last-the-glass-is-half-full (accessed 8 August 2013).

2. Goga A, Dinh TH, Jackson D, et al., the South Africa PMTCT Evaluation (SAPMTCTE) team. Impact of the national prevention of mother to child transmission of HIV (PMTCT) program on perinatal MTCT measured at 6 weeks postpartum, South Africa (SA): Results of the first year of implementation of the 2010 PMTCT Guidelines recommended by the World Health Organization (WHO). Presented at the 4th International Workshop on HIV Pediatrics. Implementation Research on PMTCT Pediatric Treatment Programmes, Washington, DC, USA, $20-21$ July 2012. Abstract $0 \_12$. http://www. mrc.ac.za/healthsystems/SAPMTCTEExecSummary2012.pdf (accessed 8 August 2013).

3. South African National AIDS Council. National Strategic Plan on HIV, STIs and TB 2012 - 2016 Pretoria: SANAC, 2011.

Pretoria: SANAC, 2011.
4. Friedman J, Sticking to the numbers: Performance monitoring in South Africa, 2009-2011. Innovations 4. Friedman J, Sticking to the numbers: Performance monitoring in South Africa, 2009-2011. Innovations
for Successful Societies, Princeton University. http://www.princeton.edu/successfulsocieties (accessed 8 for Successful Socist 2013)
5. Luvuno ZPB, Ngidi WH, Reddy J, Mhlongo O, Mate K. Leadership matters: Mobilization of province wide PMTCT team to improve key PMTCT indicators in the 11 districts of KZN province. Presented at the XIX International AIDS Conference, Washington, DC, USA, 22-27 July 2012. Poster Exhibition MOPE729. 6. Mphatswe W, Mate KS, Bennett B, et al. Improving public health information: A data quality 6. Mphatswe W, Mate KS, Bennett B, et al. Improving public health information: A data quality
intervention in KwaZulu-Natal, South Africa. Bull World Health Organ 2012;90(3):176-182. [http:// intervention in KwaZulu-Natal, South Africa. B

7. Mate K, Ngubane G, Barker PM. A quality improvement model for the rapid scale-up of a program to prevent mother-to-child HIV transmission in South Africa. Int J Qual Health Care 2003;25(4):373380. [http://dx.doi.org/10.1093/intqhc/mzt039]

8. Doherty T, Chopra M, Nsibande D, Mngoma D. Improving the coverage of the PMTCT programme through a participatory quality improvement intervention in South Africa. BMC Public Health 2009;9:406. [http://dx.doi.org/10.1186/1471-2458-9-406]

9. National Department of Health, National Action Framework for PMTCT. No child born with HIV by 2015 and improving the health and wellbeing of mothers, babies and partners in South Africa, 20122016. http://wwws sanacws.org za/af/resource-centre/download/4feac9flef9ca-version-dec-15th-actionframework-emtct-5-pdf (accessed 24 January 2014).

10. Stringer $\mathrm{E}, \mathrm{Chi} \mathrm{B}$, Chintu $\mathrm{N}$, et al. Monitoring effectiveness of programmes to prevent mother-to-child HIV transmission in lower-income countries. Bull World Health Organ 2008;86(1):57-62. [http:// dx.doi. org/10.2471/BLT.07.043117]

11. Rawizza HE. Toward eliminating pediatric HIV infection, improving retention in the PMTCT care cascade. Medscape, 2012. http://www.medscape.com/viewarticle/764394 (accessed 8 August 2013). 12. National Department of Health. Saving Mothers 2008-2010: Fifth Report on Confidential Enquiries
into Maternal Deaths in South Africa. Pretoria: $\mathrm{NDoH}, 2011$. 